Family Medicine and Community Health

\section{Discovering and doing family medicine and community health research}

\author{
Michael D Fetters, ${ }^{1}$ Timothy C Guetterman ${ }^{2}$
}

To cite: Fetters MD, Guetterman TC. Discovering and doing family medicine and community health research. Fam Med Com Health 2019;7:e000084. doi:10.1136/ fmch-2018-000084

Received 12 December 2018 Revised 17 December 2018 Accepted 24 January 2019
Check for updates

(c) Author(s) (or their employer(s)) 2019. Re-use permitted under CC BY-NC. No commercial re-use. See rights and permissions. Published by BMJ.

${ }^{1}$ Mixed Methods Program and Department of Family Medicine, University of Michigan, Ann Arbor, Michigan, USA

${ }^{2}$ Mixed Methods Program and Department of Family Medicine, University of Michigan, Ann Arbor, Michigan, USA

Correspondence to Dr Michael D Fetters; mfetters@umich.edu
We dedicate this issue to aspiring family medicine and community health researchers. We include as our audience students, residents and fellows who are still learning the craft of clinical care, clinician educators making innovative strides in teaching, and experienced clinical practitioners who are inquisitive and want to contribute to the science of family medicine and community health. In addition, we believe this issue will appeal to senior researchers and mentors as a resource to share with mentees. We now focus on why this special issue provides a unique niche for encouraging and making primary care research more accessible in primary care around the globe.

\section{LACK OF FAMILY MEDICINE RESEARCH AND NEED TO DEVELOP FUTURE LEADERS}

Modern family medicine spans more than five decades in some countries, even though many countries around the world are still family medicine-emerging countries. ${ }^{1}$ In family medicine-emerging countries, initial efforts often focus on clinical care and education, and engagement in research may be less common. But for success as an academic discipline, family medicine leaders ultimately recognise the importance of conducting original research to advance the content of clinical practice and to achieve recognition in academia. Unfortunately, the discipline of family medicine globally lacks a consistent and steady flow of original research. For example, in the 2018 Society of Teachers of Family Medicine Conference, Tammy Chang and other leading family medicine researchers conducted an entire plenary with an interactive focus designed to encourage more family physicians to problem solve the barriers and promote engagement in research. We now review why research needs to be done by primary care and community health specialists.

\section{WHY SHOULD PRIMARY CARE PROVIDERS DO RESEARCH?}

By virtue of the unique settings where they work and their scope of practice, primary care providers have unique expertise and unique challenges. As illustrated by White et al in $1961,{ }^{2}$ confirmed by Green $e t a \vec{l}^{3}$ and replicated in multiple primary settings in Japan $^{4}$ Beijing ${ }^{5}$ and Taiwan, ${ }^{6}$ the ecology of medical care illustrates the uniqueness of the primary care setting. This body of research illustrates the selection bias that occurs as patients are filtered into other specialty settings such as secondary care hospitals and tertiary care hospitals. This work conclusively demonstrates that the types of research, and by extension educational issues, that arise in primary care and ambulatory care settings systematically differ from secondary and tertiary care settings.

\section{Selection bias and chest pain}

Consider the case of chest pain as a symptom and the actual risk of significant coronary artery disease $(\mathrm{CAD})$ based on presentation to either a primary care setting or referral care setting. Sox $e t a l^{7}$ examined the prevalence of CAD in patients with similar chest pain histories, but seen in the two different settings. They compared high-disease prevalence populations, patients referred for coronary arteriography, and low-disease prevalence populations, patients from a primary care setting, in a 'drop in' clinic. Among 381 patients referred for evaluation for arteriography in the hospital, 73\% had CAD, while among 289 patients in the primary care setting only $8 \%$ had CAD. Despite having the same chest pain symptoms, Sox et $a l^{7}$ demonstrate the prevalence of CAD to be much lower among patients in primary care than tertiary care settings.

\section{Implications}

This example underscores why primary care providers need to think differently from cardiologists and other specialists. They must live on a daily basis with a different tolerance for uncertainty. Clinical reasoning for a patient with chest pain differs between primary care and academic centres. Applicable research 
questions about chest pain for primary care might include the following: What are the most common causes of chest pain in primary care? What are decision rules for identifying truly high CAD-risk patients? What are atypical presentations of CAD in primary care? Research done by other specialists may not consider differences in practice circumstances and often lack applicability to primary care providers. Primary care providers need different research from other specialists. By extension, primary care providers need to define and engage in the research that matters to them.

\section{HOW IS PRIMARY CARE EXPERTISE CONDUCIVE TO DOING RESEARCH THAT MATTERS?}

A number of research problems arise in settings that relate to the scope of primary care. Community-based care occurs in rural, suburban and urban settings in countries across the globe. The ambulatory care setting typifies the location where primary care providers work. In the ambulatory setting, the scope of practice primarily involves care of common problems. However, dealing with common problems does not necessarily suggest that the problems constitute trivial or easy problems. Primary care providers care for many patients with multiple complex problems. In many countries, they are experts in the delivery of preventive services as this comprises a central focus of primary care practice. Primary care providers provide a broad scope of care. Indeed, family medicine residency training uniquely prepares residents to care for the full spectrum of ages. The range of their training spans from preconception care, to deliveries, to newborns, children, adolescents, adult women and men, as well as elder care and end-of-life care. Other primary providers also focus on many of these same age groups.

\section{BARRIERS TO DOING RESEARCH}

Many major academic family medicine and general medicine departments have succeeded in competing for major funding and developing cutting-edge research. Still, the majority of primary care providers work on the front lines in community programmes or settings with minimal infrastructure for teaching and conducting family medicine research. These limited research infrastructure settings can be defined as any training or practice environment that has a limited number of individuals with experience in original enquiry. Such settings are characterised by limited infrastructure, for example, access to human resources for data collection, support for data analysis and mentors experienced in the academic enterprise.

\section{CHALLENGES OF CONDUCTING RESEARCH IN RESOURCE- LIMITED SETTING}

Conducting research in such limited research infrastructure settings is challenging. In addition, family medicine practitioners interested in conducting research in their clinical practice often have limited resources, time or finances, and cannot conduct large-scale projects. In limited research infrastructure settings, the desire to do research may be thwarted by lack of access to methodological references with straightforward, easy-to-understand guidance for conducting research or evaluation of common problems. Hence, a key question for those on the ground outside of the proportionately few academic family/general medicine departments in the world is how to support junior faculty, fellows, residents, medical students or even inexperienced research faculty with accessible references for conducting research.

\section{HOW THIS SPECIAL ISSUE SUPPORTS ASPIRING RESEARCHERS IN LIMITED RESEARCH INFRASTRUCTURE SETTINGS}

For this special issue, we have assembled experienced researchers, educators and clinicians who have used the featured approaches. For each article, the authors provide a short description of a specific approach and its applications. The authors also select one or more examples of published research or evaluation reports to illustrate key features. In each article, the authors provide concrete steps for conducting the project. Finally, the authors describe potential limitations and a description of other potential resources.

\section{CONTENT OF THE SPECIAL ISSUE IN DETAIL}

The issue begins with a discussion of how to get started conducting family medicine research by translating activities in day-to-day clinical practice to five steps in research: observe, ask, reflect, explore and define. In their article, Ventres and Whiteside-Mansell illustrate these steps and related questions in a practice-based research study on electronic medical records. ${ }^{8}$ Fetters then ${ }^{9}$ presents a process for helping aspiring researchers go from a general topic of interest to choosing among the various research approaches that are featured in this special issue. Next, Creswell and Hirose ${ }^{10}$ provide an accessible introduction to mixed methods research that combines qualitative and quantitative data. They illustrate six steps in a mixedmethods study using a survey and discuss an exemplar study on assessing resident physician communication and collaboration in interprofessional teams. Dejonckheere and Vaughn ${ }^{11}$ provide practical guidance for conducting semistructured interviews in primary care research. They describe 11 skills needed to balance rapport with the interviewee and methodological rigour.

The next four articles provide steps for specific types of research in primary care. Schneiderhan, Guetterman and Dobson ${ }^{12}$ turn to a common problem, the need to develop and evaluate a curriculum in medical education. Ursu, McKee and Greenberg ${ }^{13}$ discuss the steps in a rigorous, research-driven quality improvement project that they illustrate with a project conducted to improve chlamydia screening rates using the plan-do-check-act model. Next, Engelman Case, Meeks and Fetters ${ }^{14}$ 
cover steps in conducting health policy research that can be prompted by everyday dilemmas in clinical care. Fabregues and Fetters ${ }^{15}$ discuss and illustrate case study as a useful methodology in primary care research for examining in depth a phenomenon, curriculum or clinical programme in its natural setting using multiple methods to ensure the context is captured.

The final two articles discuss methods of analysis. Guetterman ${ }^{16}$ presents an overview of basic statistics used in quantitative research along with 10 steps to ensure a rigorous analysis. Babchuk ${ }^{17}$ then provides the fundamentals and history of qualitative analysis and presents a 10-step approach illustrated with an analysis of data from a study of minority health disparities.

\section{CONCLUSION}

In these pages, we provide strategies and activities based on many years of experience in engaging residents, fellows and practising clinicians in research and evaluation projects. We hope this special issue will serve as a single, online and open-access resource with strategies for taking project ideas to researchable questions or evaluations. We look forward to seeing your original research and evaluation articles in Family Medicine and Community Health.

Acknowledgements The authors greatly appreciate Rania Ajilat, who provided editing assistance.

Contributors MDF drafted the editorial, and TCG revised and edited. Both authors reviewed and agreed on the final content

Funding Funding by the University of Michigan Department of Family Medicine for the Mixed Methods Program, University of Michigan helped make this research possible.

Competing interests None declared.

Patient consent Not required.

Provenance and peer review Not commissioned; internally peer reviewed.

Open access This is an open access article distributed in accordance with the Creative Commons Attribution Non Commercial (CC BY-NC 4.0) license, which permits others to distribute, remix, adapt, build upon this work non-commercially, and license their derivative works on different terms, provided the original work is properly cited, appropriate credit is given, any changes made indicated, and the use is non-commercial. See: http://creativecommons.org/licenses/by-nc/4.0

\section{REFERENCES}

1. Fetters MD, Motohara S, Ivey L, et al. Utility of self-competency ratings during residency training in family medicine educationemerging countries: findings from Japan. Asia Pac Fam Med $2017 ; 16$.

2. White KL, Williams TF, Greenberg BG. The ecology of medical care. N Engl J Med 1961;265:885-92.

3. Green LA, Fryer GE, Yawn BP, et al. The ecology of medical care revisited. N Engl J Med 2001;344:2021-5.

4. Fukui T, Rhaman M, Takahashi $\mathrm{O}$, et al. The ecology of medical care in Japan. Japan Medical Association Journal 2005;48:163-7.

5. Shao S, Zhao F, Wang J, et al. The ecology of medical care in Beijing. PLoS One 2013;8:e82446.

6. Chang CP, Chou CL, Chou YC, et al. The ecology of gynecological care for women. Int J Environ Res Public Health 2014;11:7669-77.

7. Sox HC, Hickam DH, Marton KI, et al. Using the patient's history to estimate the probability of coronary artery disease: a comparison of primary care and referral practices. Am J Med 1990;89:7-14.

8. Ventres W, Whiteside-Mansell L. Getting started in research, redefined: five questions for clinically focused physicians in family medicine. Fam Med Com Health 2019;7:e000017.

9. Fetters MD. Getting started in primary care research: choosing among six practical research approaches. Fam Med Com Health 2019;7:e000042.

10. Creswell JC, Hirose M. Mixed methods and survey research infamily medicine and community health. Fam Med Com Health 2019;7:e000086.

11. Dejonckheere M, Vaughn LM. Semistructured interviewing in primary care research: a balance of relationship and rigour. Fam Med Com Health 2019;7:e000057.

12. Schneiderhan J, Guetterman TC, Dobson ML. Curriculum development: a how to primer. Fam Med Com Health 2019;7:e000046.

13. Ursu A, Greenberg G, McKee M. Continuous quality improvement methodology: a case study on multidisciplinary collaboration to improve Chlamydia screening. Fam Med Com Health 2019;7:e000085.

14. Engelman A, Case B, Meeks L, et al. Conducting health policy analysis in primary care research: turning clinical ideas into action. Fam Med Com Health 2019;7:e000076.

15. Fàbregues S, Fetters MD. Fundamentals of case study research in family medicine and community health. Fam Med Com Health 2019;7:e000074.

16. Guetterman TC. Basics of statistics for primary care research. Fam Med Com Health 2019;7:e000067.

17. Babchuk WA. Fundamentals of qualitative analysis infamily medicine. Fam Med Com Health 2019;7:e000040. 